\title{
Uric acid and blood pressure
}

Citation for published version (APA):

Scheepers, L. E. J. M., Boonen, A., Dagnelie, P. C., Schram, M. T., van der Kallen, C. J. H., Henry, R. M. A., Kroon, A. A., Stehouwer, C. D. A., \& Arts, I. C. W. (2017). Uric acid and blood pressure: exploring the role of uric acid production in The Maastricht Study. Journal of Hypertension, 35(10), 1968-1975. https://doi.org/10.1097/HJH.0000000000001417

Document status and date:

Published: 01/10/2017

DOI:

10.1097/HJH.0000000000001417

Document Version:

Publisher's PDF, also known as Version of record

Document license:
Taverne

\section{Please check the document version of this publication:}

- A submitted manuscript is the version of the article upon submission and before peer-review. There can be important differences between the submitted version and the official published version of record.

People interested in the research are advised to contact the author for the final version of the publication, or visit the DOI to the publisher's website.

- The final author version and the galley proof are versions of the publication after peer review.

- The final published version features the final layout of the paper including the volume, issue and page numbers.

Link to publication

\footnotetext{
General rights rights.

- You may freely distribute the URL identifying the publication in the public portal. please follow below link for the End User Agreement:

www.umlib.nl/taverne-license

Take down policy

If you believe that this document breaches copyright please contact us at:

repository@maastrichtuniversity.nl

providing details and we will investigate your claim.
}

Copyright and moral rights for the publications made accessible in the public portal are retained by the authors and/or other copyright owners and it is a condition of accessing publications that users recognise and abide by the legal requirements associated with these

- Users may download and print one copy of any publication from the public portal for the purpose of private study or research.

- You may not further distribute the material or use it for any profit-making activity or commercial gain

If the publication is distributed under the terms of Article $25 \mathrm{fa}$ of the Dutch Copyright Act, indicated by the "Taverne" license above, 


\title{
Original Article
}

\section{Uric acid and blood pressure: exploring the role of uric acid production inThe Maastricht Study}

\author{
Lieke E.J.M. Scheepers $^{a, b}$, Annelies Boonen ${ }^{a, b}$, Pieter C. Dagnelie $^{b, c, d}$, Miranda T. Schram ${ }^{c, e, f}$, \\ Carla J.H. van der Kallen ${ }^{c, e}$, Ronald M.A. Henry ${ }^{c, e, f}$, Abraham A. Kroon ${ }^{c, e, f}$, Coen D.A. Stehouwer ${ }^{c, e}$, \\ and Ilja C.W. Arts ${ }^{c, d, g}$
}

\begin{abstract}
Objective: Accumulation of reactive oxygen species by increased uric acid production has been suggested as a possible underlying mechanism for the association between uric acid and high blood pressure (BP). We, therefore, investigated the association between serum uric acid concentration and 24-h urinary uric acid excretion, as proxy for uric acid production, with ambulatory 24-h blood pressure and hypertension.
\end{abstract}

Methods: Cross-sectional analyses were conducted among 2555 individuals [ $52 \%$ men, mean age $60.0 \pm 8.2$ years; 27\% type 2 diabetes (by design)] from The Maastricht Study. Multivariable regression analyses were performed to investigate the association of serum uric acid and 24-h urinary uric acid excretion with 24-h pulse pressure, 24-h mean arterial pressure (MAP), and hypertension.

Results: After adjustment for traditional hypertension risk factors, serum uric acid concentration (per SD of $81 \mu \mathrm{mol} / \mathrm{l})$ was associated with higher $24-\mathrm{h}$ MAP [ $\beta$ $0.63 \mathrm{mmHg}$; confidence interval (Cl) $0.27-1.00$ ] and positively associated with hypertension (odds ratio 1.43; Cl 1.27-1.61). Urinary uric acid excretion (per SD of $140 \mathrm{mg} /$ day $/ 1.73 \mathrm{~m}^{2}$ ) was associated with higher $24-\mathrm{h}$ MAP $(\beta 0.79 \mathrm{mmHg} ; \mathrm{Cl} 0.46-1.12)$ and with hypertension (odds ratio $1.13 ; \mathrm{Cl} 1.02-1.25)$. There was no significant association between serum and 24-h urinary uric acid excretion with 24-h pulse pressure. There was no interaction with sex or age for the aforementioned associations.

Conclusion: Higher serum and urinary uric acid concentrations were associated with higher 24-h MAP and hypertension. These results suggest that serum and 24urinary uric acid concentrations, the latter as proxy for uric acid production are, independent of each other, associated with BP and hypertension.

Keywords: blood pressure, hypertension, mean arterial pressure, pulse pressure, reactive oxygen species, uric acid, xanthine dehydrogenase, xanthine oxidase, xanthine oxidoreductase
Abbreviations: $\mathrm{BP}$, blood pressure; $\mathrm{Cl}$, confidence interval; eGFR, estimated glomerular filtration rate; MAP, mean arterial pressure; OR, odds ratio; $\mathrm{PP}$, pulse pressure; RAAS, renin-angiotensin-aldosterone system; ROS,

reactive oxygen species; T2DM, type 2 diabetes mellitus; UA, uric acid

\section{INTRODUGTION}

\lceil ric acid, the final product of purine catabolism, has been associated with blood pressure (BP) and hypertension. Recent meta-analyses showed a significant association between serum uric acid and incident hypertension, independent of traditional risk factors $[1,2]$. Several plausible mechanisms have been proposed that causally link uric acid with elevated BP and hypertension. One mechanism includes the activation of the reninangiotensin-aldosterone system (RAAS) by elevated concentrations of uric acid, leading to increased production of the vasoconstrictor angiotensin II [3]. Another possible mechanism not directly related to uric acid concentration, but rather to its production, is the generation of reactive oxygen species (ROS) during the production of uric acid. The enzyme xanthine oxidoreductase catalyzes the breakdown of hypoxanthine to xanthine and the latter to uric acid. When oxygen is the electron acceptor, superoxide radical anion $\left(\mathrm{O}_{2}-\right)$ [4] and hydrogen peroxide $\left(\mathrm{H}_{2} \mathrm{O}_{2}\right)$ are generated as by-products of the oxidation step. These ROS directly reduce the bioavailability of the vasodilator nitric oxide and lead to the formation of peroxynitrite, which can increase endothelial nitric oxide synthase uncoupling resulting in even more ROS formation [5,6].

Studies published so far have focused mostly on serum uric acid and have ignored the distinction between uric acid concentration and its production. As the production of uric

Journal of Hypertension 2017, 35:1968-1975

${ }^{a}$ Division of Rheumatology, Department of Internal Medicine, Maastricht University Medical Centre, ${ }^{b}$ CAPHRI School for Public Health and Primary Care, 'CARIM School for Cardiovascular Diseases, ${ }^{\mathrm{d} D e p a r t m e n t}$ of Epidemiology, Maastricht University, eDepartment of Internal Medicine, ${ }^{\mathrm{f}}$ Heart and Vascular Centre, Maastricht University Medical Centre and ${ }^{9} \mathrm{MaCSBio}$ Maastricht Centre for Systems Biology, Maastricht University, Maastricht, The Netherlands

Correspondence to Lieke E.J.M. Scheepers, MSc, Ing, Department of Rheumatology, Maastricht University Medical Centre, Postbus 5800, 6202 AZ Maastricht, The Netherlands. Tel: +00316 18984522; fax: +0031 433 875006;

e-mail: lieke.scheepers@maastrichtuniversity.nl

Received 3 November 2016 Revised 27 March 2017 Accepted 14 April 2017 J Hypertens 35:1968-1975 Copyright (C) 2017 Wolters Kluwer Health, Inc. All rights reserved.

DOI:10.1097/HJH.0000000000001417 


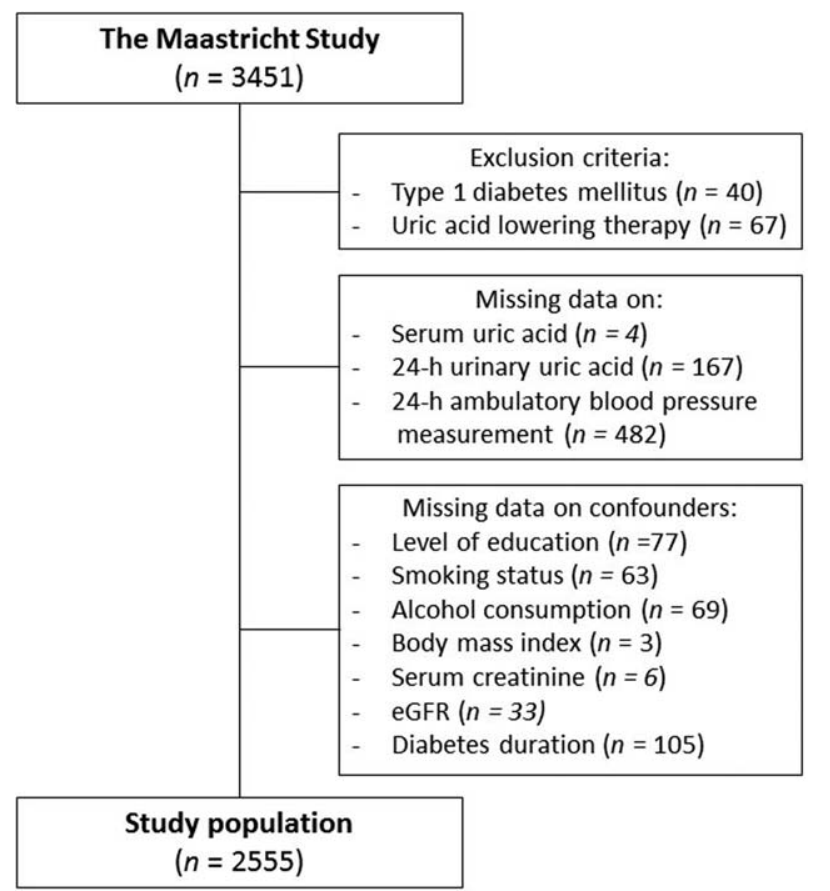

FIGURE 1 Flow-chart of study participants. eGFR, estimated glomerular filtration rate.

acid may contribute, independent of uric acid concentration, to the pathogenesis of hypertension, the production should be investigated as well [7]. Facing the problem that it is not possible to directly measure uric acid production in a large population of individuals, and that uric acid concentration is not an adequate marker for production, proxies for uric acid production need to be investigated. Under normal conditions, the body compensates for increased uric acid production by increasing uric acid excretion, so that serum uric acid remains stable and within the normal range of $200-430 \mu \mathrm{mol} / 1$ for men and $120-340 \mu \mathrm{mol} / 1$ for women [8]. Uric acid is predominantly excreted via the urine; therefore, we used 24-h urinary uric acid excretion as a proxy for uric acid production.

In view of the above, we aimed to evaluate whether serum uric acid concentration and/or 24-h urinary uric acid excretion, as proxy for uric acid production are, independent of each other, associated with 24-h ambulatory BP and hypertension. We analysed the pulsatile and steady component of BP captured by 24-h pulse pressure (PP) and 24-h mean arterial pressure (MAP), respectively.

\section{METHODS}

\section{Study population and design}

We used data from The Maastricht Study, an observational prospective cohort study. The rationale and methodology have been described previously [9]. In brief, the study focuses on the aetiology, pathophysiology, complications and comorbidities of type 2 diabetes mellitus (T2DM) and is characterized by an extensive phenotyping approach. Eligible for participation were all individuals aged between 40 and 75 years and living in the southern part of The
Netherlands. Participants were recruited through mass media campaigns and from municipal registries and the regional Diabetes Patient Registry through mailings. Recruitment was stratified according to known T2DM status, with an oversampling of individuals with T2DM, for reasons of efficiency. The present report includes crosssectional data from the first 3451 participants, who completed the baseline survey between November 2010 and September 2013. The examinations of each participant were performed within a time window of 3 months. The study has been approved by the institutional medical ethical committee (NL31329.068.10) and the Minister of Health, Welfare and Sports of The Netherlands (Permit 131088-105234-PG). All participants gave written informed consent.

For the present study, we excluded individuals without data on serum uric acid $(n=4)$, creatinine $(n=6)$, 24-h urine collection $(n=167)$, ambulatory BP $(n=482)$, level of education $(n=77)$, smoking status $(n=63)$, alcohol consumption $(n=69)$, BMI $(n=3)$, estimated glomerular filtration rate (eGFR; $n=33$ ), or diabetes duration $(n=105)$. We also excluded individuals with type 1 diabetes mellitus $(n=40)$ or on uric acid lowering therapy (i.e. allopurinol, benzbromarone; $n=67$ ). A total of 2555 individuals were included in the present analyses (Fig. 1).

\section{Twenty-four-hour ambulatory blood pressure measurement}

Ambulatory BP was measured with ambulatory 24-h BP monitoring (WatchBP O3; Microlife AG, Widnau, Switzerland). Cuffs were applied to the participants' nondominant arm. Measurements were done every 15 min during daytime $(0800-2300 \mathrm{~h})$ and every $30 \mathrm{~min}$ during the night (2300-0800 h) for a total of $24 \mathrm{~h}$. Mean 24-h BP measurements were only calculated if there were more than 14 valid measurements at daytime and less than seven valid measurements at night, according to the recommendation of the British Hypertension Society [10]. Mean 24-h SBP and DBP were calculated based on hourly averages [11]. Twenty four-hour mean PP was defined as 24-h SBP-24-h DBP, and MAP as mean 24-h DBP $+(0.412 \times$ mean $24-h$ PP $)$ [12]. Hypertension was defined as the use of antihypertensive medication, mean 24-h SBP of at least $135 \mathrm{mmHg}$, or mean 24-h DBP of at least $85 \mathrm{mmHg}$ [13]. Use of antihypertensive medication was assessed during a medication interview, where generic name, dose, and frequency were registered.

\section{Uric acid determination}

After an overnight fast, venous blood samples were collected to assess serum uric acid and creatinine concentrations with standard (enzymatic and/or colorimetric) methods by an automatic analyzer [Beckman Synchron LX20; Beckman Coulter Inc., Brea California, USA or the Roche Cobase601 hs-cTnT assay (F Hoffmann-La Roche, Basel, Switzerland) on the Cobas 6000 analyzer for the last 2585 samples] at Maastricht University Medical Centre (The Netherlands).

To assess urinary uric acid and creatinine excretion, participants were requested to collect a 24 -h urine sample. 
Participants were instructed both orally and in writing on the procedure concerning the 24-h urine collection. Only urine collections with a collection time between 20 and 28-h were considered valid, in case of violation participants were asked to collect urine once more. Urinary uric acid and creatinine concentration were measured with a standard immunoturbidimetric assay by an automatic analyzer (Beckman Synchron LX20; Beckman Coulter Inc.) and multiplied by collection volume to obtain the 24-h urinary uric acid excretion. According to the DuBois and DuBois equation, 24-h urinary uric acid and creatinine excretion were adjusted for body surface [14].

\section{Covariates}

To determine diabetes status, all participants (except those who use insulin) underwent a standardized 2-h $75 \mathrm{~g}$ oral glucose tolerance test after an overnight fast as previously described [9]. Glucose metabolism was defined according to the WHO 2006 criteria into normal glucose metabolism, impaired fasting glucose, impaired glucose tolerance, and T2DM [15]. For this study, we defined having either impaired fasting glucose or impaired glucose tolerance as prediabetes.

Weight and height were measured without shoes and wearing light clothing using a scale and stadiometer to the nearest $0.5 \mathrm{~kg}$ or $0.1 \mathrm{~cm}$ (Seca, Hamburg, Germany). BMI was calculated as body weight $(\mathrm{kg})$ divided by height squared $\left(\mathrm{m}^{2}\right)$. Waist and hip circumference were measured in duplicate midway between the lower rib margin and the iliac crest at the end of expiration and at the widest level over the greater trochanters, respectively (Seca, Hamburg, Germany). Waist-to-hip ratio was calculated as the mean of two waist circumference measurements divided by the mean of two hip circumference measurements. As previously described [9], diabetes duration, education level, smoking status, and alcohol consumption were assessed by means of a self-reported questionnaire. Level of education was self-reported and classified into eight categories: no education; primary education; lower vocational education; intermediate general secondary education; intermediate vocational education; higher general secondary education; higher vocational education; and university. For this study, three groups were created for educational level: low (levels 1-3), middle (levels 4-6), and high (levels 7 and 8). Smoking status was based on self-report of smoking cigarettes, cigars, and/or pipe tobacco and divided into three categories, that is, nonsmoker, former smoker, and current smoker. Alcohol consumption was self-reported as the number of alcohol consumptions/week. One standard alcohol consumption is equivalent to $10 \mathrm{~g}$ (or $13 \mathrm{ml}$ ) alcohol. This corresponds to one glass of beer of $250 \mathrm{ml}(5 \%$ alcohol), one glass of wine of $100 \mathrm{ml}$ ( $12 \%$ alcohol), or one glass of spirit of $35 \mathrm{ml}$ (35\% alcohol) [16]. For analyses, total alcohol consumption was evaluated in grams of alcohol/ week. The patients were grouped into three categories, that is, nonconsumers ( $0 \mathrm{~g}$ of alcohol/week), low consumers ( $\leq 70 \mathrm{~g}$ of alcohol/week for females and $\leq 140 \mathrm{~g}$ of alcohol/ week for males), and high consumers ( $>70 \mathrm{~g}$ of alcohol/ week for females and $>140 \mathrm{~g}$ of alcohol/week for males). Physical activity was determined from the Community Healthy Activities Model Program for Seniors (CHAMPS) questionnaire (h/week). Activities accounted were walking, cycling, gardening, household work, jogging/running, swimming, tennis, team sport, and exercise, regardless whether the activity was on a light or intense. GFR was estimated using the Chronic Kidney Disease Epidemiology Collaboration (CKD-EPI) equation based on both serum creatinine and serum cystatin C [17]. Use of uric acid lowering (allopurinol, febuxostat, probenecid, benzbromarone) and glucose-lowering medication were as well assessed during the medication interview.

\section{Statistical analysis}

The characteristics of the participants are given as mean values \pm SD for continuous variables and as numbers and proportions for categorical variables. To check if urinary uric acid excretion is an independent marker and does not represent serum uric acid concentration we created a scatterplot and calculated the $R^{2}$ between those two variables.

Multiple linear or logistic regression analyses were used to determine the association between the independent variables serum uric acid concentration and 24-h urinary uric acid excretion with the dependent variables ambulatory 24-h PP, 24-h MAP, and the odds ratio (OR) of prevalent hypertension. In the first model, the results of the crude analyses were presented. In the second model, crude results were adjusted for sex, age, glucose metabolism status, smoking status, alcohol consumption, eGFR, level of education, use of diabetes medication (no, oral medication, insulin with or without oral medication), RAAS inhibitors and other antihypertensive medication (including $\beta$-blockers) that have no known uricosuric properties, losartan (known as a RAAS inhibitor with a uricosuric effect) $[18,19]$, and antihypertensive medication and lipidlowering medication that may have a uricosuric effect (i.e. secondary uricosurics, amlodipine [20], atorvastatin [21], rosuvastatin [21]). In the third model, the analyses with serum uric acid were additionally adjusted for 24-h urinary uric acid excretion; and the associations with 24-h urinary uric acid excretion were additionally adjusted for serum uric acid. To explore if serum and urinary uric acid concentrations are, independent of each other, associated with $\mathrm{BP}$ and hypertension, the logistic regression models were adjusted for the same covariates, except for the use of antihypertensive medication, which is part of the definition of the outcome.

As it has been suggested that uric acid has a more pronounced effect in younger and female individuals, we investigated whether the association between serum uric acid concentration and urine uric acid excretion with ambulatory BP and hypertension differed with sex and age [22-25].

As an elevated uric acid may be a consequence of a high BMI or waist-to-hip ratio, adjustment for BMI or waist-tohip ratio in the analyses may lead to overadjustment and these variables were, therefore, not included in the main analyses. In a sensitivity analysis, we additionally adjusted for BMI or waist-to-hip ratio [26]. Owing to the large number of missing values on physical activity $(n=278)$ this variable was not included as potential confounder in the main analyses. A sensitivity analysis was performed to 
TABLE 1. Characteristics of The Maastricht Study population and the individuals excluded from the analyses because of missing values

\begin{tabular}{|c|c|c|c|}
\hline & Study population $(n=2555)$ & Missing & $\begin{array}{c}\text { Excluded because of missing } \\
\text { values }(n=896)\end{array}$ \\
\hline Serum uric acid ( $\mu \mathrm{mol} / \mathrm{l})$ & $329.3 \pm 81.3$ & 6 & $331.8 \pm 85.00$ \\
\hline Serum creatinine $(\mu \mathrm{mol} / \mathrm{l})$ & $77.2 \pm 16.1$ & 4 & $77.4 \pm 17.7$ \\
\hline Urine uric acid excretion (mg/day per $1.73 \mathrm{~m}^{2}$ ) & $518.1 \pm 139.92$ & 127 & $507.5 \pm 181.6$ \\
\hline Urine creatinine excretion (mmol/day per $1.73 \mathrm{~m}^{2}$ ) & $12.0 \pm 2.8$ & 78 & $11.9 \pm 4.1$ \\
\hline Fractional uric acid excretion ( $\mathrm{FE}_{\mathrm{UA}}$ ) & $9.3 \% \pm 5.3$ & 173 & $9.5 \% \pm 10.4$ \\
\hline Age (years) & $59.8 \pm 8.1$ & 0 & $59.6 \pm 8.6$ \\
\hline Male sex $(n)$ & $51.0 \%(1303)$ & 0 & $52.7 \%(472)$ \\
\hline BMI $\left(\mathrm{kg} / \mathrm{m}^{2}\right)$ & $26.8 \pm 4.3$ & 5 & $27.9 \pm 5.1$ \\
\hline Waist-to-hip ratio & $0.94 \pm 0.09$ & 4 & $0.96(0.10)$ \\
\hline Smoking status, $(n)$ & & 63 & \\
\hline Never & $35.9 \%(916)$ & & $28.3 \%(254)$ \\
\hline Past & $52.2 \%(1333)$ & & $46.4 \%(416)$ \\
\hline Current & $12.0 \%(306)$ & & $18.2 \%(163)$ \\
\hline Alcohol consumption, $(n)$ & & 69 & \\
\hline No & $16.9 \%(432)$ & & $22.0 \%(197)$ \\
\hline Low & $56.6 \%(1446)$ & & $47.9 \%(429)$ \\
\hline High & $26.5 \%(677)$ & & $22.4 \%(201)$ \\
\hline Educational level, $(n)$ & & 77 & \\
\hline Low & $31.4 \%(801)$ & & $37.1 \%(332)$ \\
\hline Medium & $28.6 \%(731)$ & & $24.8 \%(222)$ \\
\hline High & $40.0 \%(1023)$ & & $29.6 \%(265)$ \\
\hline Physical activity (hours/week) ${ }^{a}$ & $14.5 \pm 8.2$ & 179 & $13.0 \pm 7.8$ \\
\hline eGFR $\left(\mathrm{ml} / \mathrm{min}\right.$ per $\left.1.73 \mathrm{~m}^{2}\right)$ & $88.25 \pm 14.50$ & 55 & $87.7 \pm 16.5$ \\
\hline Glucose metabolism status, $(n)$ & & 0 & \\
\hline Normal glucose metabolism & $60.6 \%(1549)$ & & $41.9 \%(375)$ \\
\hline Impaired fasting glucose & $4.3 \%(111)$ & & $3.6 \%(32)$ \\
\hline Impaired glucose tolerance & $11.3 \%(289)$ & & $8.8 \%(79)$ \\
\hline Type 2 diabetes mellitus & $23.7 \%(606)$ & & $41.2 \%(369)$ \\
\hline Other type of diabetes & $\mathrm{n} / \mathrm{a}$ & & $4.5 \%(41)$ \\
\hline Diabetes treatment among individuals with T2DM, $(n)$ & 4 & & \\
\hline No medication & $25.1 \%(152)$ & & $15.5 \%(57)$ \\
\hline Oral medication & $55.0 \%(333)$ & & $58.7 \%(216)$ \\
\hline Insulin with or without oral medication & $20.0 \%(121)$ & & $25.8 \%(95)$ \\
\hline Diabetes duration (years), median (range) & $8.4 \pm 7.2$ & 178 & $7.4 \pm 6.9$ \\
\hline Hypertension (\%) & $43.2 \%(1103)$ & 406 & $59.8 \%(293)$ \\
\hline Use of antihypertensive medication, $(n)$ & $37.1 \%(947)$ & 4 & $44.6 \%(353)$ \\
\hline RAAS-inihibitors & $24.7 \%(631)$ & & $34.3 \%(307)$ \\
\hline Other antihypertensives, no uricosuric effect & $20.6 \%(527)$ & & $30.7 \%(275)$ \\
\hline Losartan & $2.9(75)$ & & $3.8 \%(34)$ \\
\hline Secondary uricosuric & $13.5 \%(346)$ & & $20.4 \%(182)$ \\
\hline Mean arterial pressure $24-\mathrm{h}(\mathrm{mmHg})$ & $88.5 \pm 7.9$ & 404 & $89.8 \pm 8.5$ \\
\hline Pulse pressure $24-\mathrm{h}(\mathrm{mmHg})$ & $45.2 \pm 8.5$ & 404 & $47.5 \pm 9.8$ \\
\hline
\end{tabular}

Data are presented as mean and SD unless otherwise indicated.

eGFR, estimated glomerular filtration rate; $F_{U A}$, fractional excretion of uric acid; RAAS, renin-angiotensin-aldosterone system; T2DM, type 2 diabetes mellitus.

${ }^{a}$ Missing data for 278 individuals on variable physical activity.

control for this variable in the subset of participants with complete data.

The null hypothesis was rejected for a two-sided $P$ value was less than 0.05 , except for the interaction analyses, where a $P$ value less than 0.10 was used. Analyses were conducted using SPSS version 23 for windows (SPSS, Inc., Chicago, Illinois, USA).

\section{RESULTS}

The overall study population consisted of 2555 individuals with an average age of 59.8 (SD 8.1) years, 51\% of whom were men. Owing to oversampling of individuals with diabetes $24 \%$ ( $n=606$ ) had T2DM. Table 1 shows the general characteristics of the study population and the individuals excluded from the analyses. On average the serum uric acid concentration was $329 \mu \mathrm{mol} / 1$ (SD 81) and 24-h urinary uric excretion was $518 \mathrm{mg} / \mathrm{min}$ per $1.73 \mathrm{~m}^{2}$ (SD 140). In total 1103 individuals (43\%) had hypertension, of these 947 (86\%) were on antihypertensive medication. In the remaining 156 patients (14\%), the diagnosis of hypertension relied on the threshold being exceeded for SBP $(n=49 ; 31 \%)$, DBP ( $n=45 ; 29 \%)$, or both $(n=62 ; 40 \%)$. Individuals excluded from analyses had a lower level of education, slightly higher BMI, and were more often T2DM or hypertensive patients.

The variance in serum uric acid, while significant ( $P$ value $<0.001$ ), explains only $0.9 \%$ of the variance in urinary uric acid excretion (Fig. 2).

\section{Serum uric acid and 24-h blood pressure}

Crude linear regression analysis showed that a one SD (81 $\mu \mathrm{mol} / \mathrm{l})$ higher serum uric acid concentration was associated with $1.73 \mathrm{mmHg}$ (CI, 1.44 to $2.02 \mathrm{mmHg}$ ) higher 


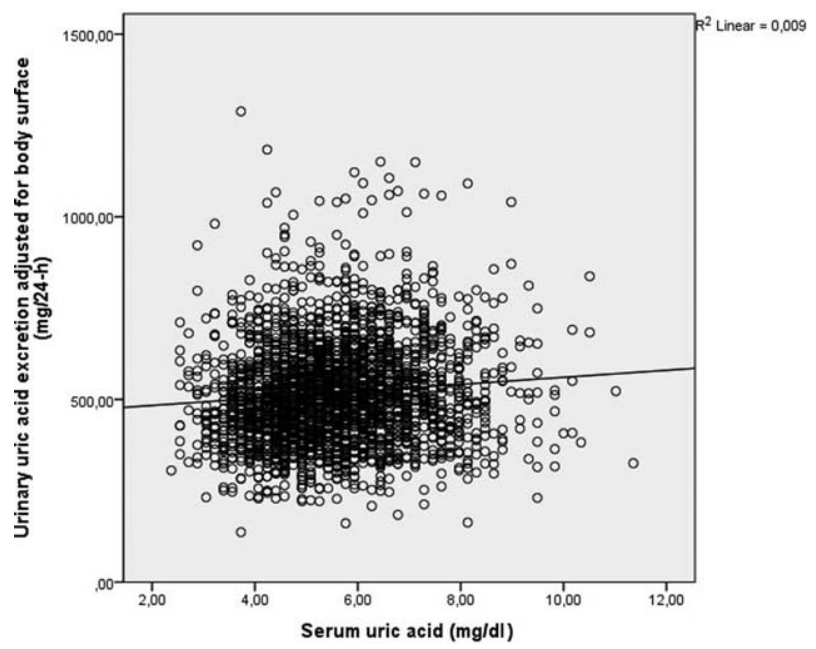

FIGURE 2 Uric acid excretion in 24-h urine $\left(\mathrm{mg} / 1.73 \mathrm{~m}^{2}\right)$ as a function of serum uric acid $(\mathrm{mg} / \mathrm{dl})$ in 2555 participants from The Maastricht Study.

24-h MAP and greater odds for hypertension (OR 1.89; CI, 1.73-2.07; Table 2, model 1). Further adjustment for sex, age, and glucose metabolism status, smoking status, alcohol consumption, education, eGFR, duration of diabetes and use of antihypertensive, or diabetes medication, did not materially change the result (model 2). Furthermore, results remained significant with additional adjustment for 24-h urinary uric acid excretion (model 3). The association with 24-h PP was significant in the crude analysis (Table 2, model 1), but lost significance after adjustment for potential confounders (models 2 and 3).

\section{Twenty-four-hour urine uric acid excretion and twenty-four-hour blood pressure}

Crude linear regression analysis showed that a one SD higher 24-h urinary uric acid excretion (140 mg/day per $\left.1.73 \mathrm{~m}^{2}\right)$ was associated with higher 24-h MAP ( $\beta$ 1.98; CI, $1.69-2.28 \mathrm{mmHg}$ ) and greater odds for hypertension (OR 1.26; CI 1.16-1.36; Table 2, model 1). The associations of serum uric acid with 24-h MAP and hypertension did not materially change after further adjustment for potential confounders (model 2). Further adjustment for serum uric acid concentration did not materially changes the results (model 3). The association between urinary uric acid excretion and 24-h PP was significant in the crude analysis ( $\beta$ 1.10; CI, $0.77-1.42 \mathrm{mmHg}$ ), but lost significance after adjustment for potential confounders (Table 2, models 2 and $3 ; P$ value $<0.15$ ).

\section{Effect modification by age or sex}

To determine whether the associations between serum uric acid and urine uric acid excretion with ambulatory PP, MAP, and hypertension were different across sex and age strata, an interaction term was added to the fully adjusted regression models. No significant interaction with sex or age was identified in any of the investigated associations $(P$ value $>0.10)$.

\section{Sensitivity analyses}

Including BMI or waist-to-hip ratio as a covariate to model 3 did not materially alter the associations between serum uric acid and BP or hypertension. However, the association between urinary uric acid excretion and hypertension was attenuated after including both BMI (OR 0.99; $P=0.80$ ) and waist-to-hip ratio (OR 1.04; $P=0.45$ ).

Additional adjustment for physical activity did not materially alter the associations of serum uric acid and urinary uric acid excretion with ambulatory PP, MAP, and hypertension (data not shown).

\section{DISGUSSION}

The study represents a comprehensive analysis of the association of uric acid with ambulatory BP and hypertension in middle-aged individuals. Serum uric acid concentration and 24-h urinary uric acid excretion, as proxy for uric acid production, were independent of each other associated with ambulatory MAP and hypertension. To the best of our knowledge, this study is the first to show an

TABLE 2. Associations between serum uric acid and urinary uric acid excretion with ambulatory mean arterial pressure, pulse pressure and hypertension

\begin{tabular}{|c|c|c|c|c|c|c|c|c|c|}
\hline & \multicolumn{2}{|c|}{$\begin{array}{c}\text { Mean arterial } \\
\text { pressure }\end{array}$} & \multirow[b]{2}{*}{$P$ value } & \multicolumn{2}{|c|}{$\begin{array}{c}\text { Pulse } \\
\text { pressure }\end{array}$} & \multirow[b]{2}{*}{$P$ value } & \multicolumn{2}{|c|}{ Hypertension $^{\text {a }}$} & \multirow[b]{2}{*}{$P$ value } \\
\hline & \multicolumn{2}{|c|}{$\beta(95 \% \mathrm{Cl})$} & & \multicolumn{2}{|c|}{$\beta(95 \% \mathrm{Cl})$} & & \multicolumn{2}{|c|}{ Odds ratio $(95 \% \mathrm{Cl})$} & \\
\hline \multicolumn{10}{|c|}{ Serum uric acid $^{b}$} \\
\hline Model 1 & 1.73 & $(1.44-2.03)$ & $<0.001$ & 1.70 & $(1.37-2.02)$ & $<0.001$ & 1.89 & $(1.73-2.07)$ & $<0.001$ \\
\hline Model 2 & 0.70 & $(0.35-1.07)$ & $<0.001$ & 0.09 & $(-0.28-0.45)$ & 0.65 & 1.45 & $(1.29-1.63)$ & $<0.001$ \\
\hline Model 3 & 0.63 & $(0.27-1.00)$ & $<0.01$ & 0.08 & $(-0.30-0.43)$ & 0.73 & 1.43 & $(1.27-1.61)$ & $<0.001$ \\
\hline \multicolumn{10}{|c|}{ Uric acid excretion ${ }^{c}$} \\
\hline Model 1 & 1.98 & $(1.69-2.28)$ & $<0.001$ & 1.10 & $(0.77-1.42)$ & $<0.001$ & 1.26 & $(1.16-1.36)$ & $<0.001$ \\
\hline Model 2 & 0.84 & $(0.51-1.16)$ & $<0.001$ & 0.24 & $(-0.08-0.57)$ & 0.15 & 1.16 & $(1.04-1.28)$ & $<0.01$ \\
\hline Model 3 & 0.79 & $(0.46-1.12)$ & $<0.001$ & 0.24 & $(-0.09-0.57)$ & 0.15 & 1.13 & $(1.02-1.25)$ & 0.03 \\
\hline
\end{tabular}

Medication: in the adjusted analyses, no adjustment for antihypertensive medication.

Model 1: crude. Model 2 adjusted for age, sex, glucose metabolism status (normal, impaired, T2DM), smoking status (never, current, former), alcohol consumption (no, low, high),

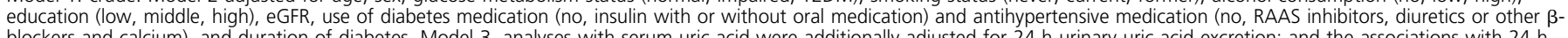

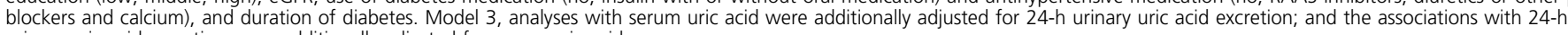

urinary uric acid excretion were additionally adjusted for serum uric acid.

$\mathrm{Cl}$, confidence interval.

a Hypertension is defined as a 24-h SBP of more than 135, or DBP more than 85 or the use of antihypertensive

${ }^{b}$ Serum uric acid expressed/SD $(81 \mu \mathrm{mol} / \mathrm{l})$

CUric acid excretion in 24-h urine expressed/SD (140 mg/day/1.73 $\left.\mathrm{m}^{2}\right)$. 
independent association of 24-h urinary uric acid excretion, as proxy for uric acid production, with ambulatory BP and hypertension.

Our results are in line with prior research showing that serum uric acid was associated with hypertension, independent of traditional hypertension risk factors [2]. A meta-analysis performed by Wang et al. in 2014 [2], showed that a $1 \mathrm{mg} / \mathrm{dl}$ increase in uric acid was associated with an increased risk of incident hypertension (adjusted relative risk 1.15; CI, 1.06-1.26). In the current cross-sectional study, a similar OR of 1.20 (CI, 1.10-1.31) for each $1 \mathrm{mg} / \mathrm{dl}$ higher serum uric acid concentration was found. In the present study, we found no age or sex-related difference in the association between serum uric acid and any of the outcomes. This is in contrast with the meta-analysis performed by Grayson et al. [1] which showed that the risk of hypertension among individuals with hyperuricemia was significantly larger in younger individuals and women. This contrasting finding may be attributed to the inclusion criterium of an age of 40 years and older, resulting in a relative high age of our study population (mean age of 60.0 years).

There are no earlier studies examining the association between urinary uric acid excretion, as proxy for uric acid production, and BP. We showed that urinary uric acid excretion was significantly associated with ambulatory MAP and hypertension, after adjustment for potential confounders including serum uric acid. These findings confirm our hypothesis that increased uric acid production is associated with BP and hypertension. Uric acid is produced during the metabolism of endogenous (DNA, RNA, and ATP) and exogenous (dietary) purines. Previous studies showed that an increase in uric acid production, either by endogenous or exogenous supply, increases urinary uric acid excretion [8]. Approximately, $70 \%$ of the produced uric acid is eliminated by the kidney and $30 \%$ by the intestine (extra-renal pathway), whether the relative contribution of renal and extra-renal excretion is comparable in case of increased uric acid production needs investigation [27]. In case of decreased extra-renal excretion, serum uric acid and urinary uric acid excretion will increase. Among white individuals approximately 11\% (Haplotype Mapping, Han Chinese in Beijing, Japanese in Tokyo) has the Q141K mutation in the urate transport $A B C G 2$, which leads to a decrease in extra-renal uric acid excretion, causing increased serum and urinary uric acid concentrations and eventually gout [28-30]. Theoretically, the 'overproducers' in the current concept, those with increased urinary uric acid excretion, may include next to the genuine 'uric acid overproducers' also 'underexcretors of uric acid via the intestine (extra-renal elimination)' [28]. Unfortunately, it is not feasible to determine uric acid excretion via the intestine since it is degraded by uricase activity of the intestinal microbiota, leading to an almost complete lack of uric acid in the feces [31]. However, by excluding patients on uric acid lowering therapy, we have attempted to exclude those with gout and therefore possibly with decreased renal or extra-renal excretion.

In addition, oxidation of hypoxanthine to xanthine does not have to be equivalent to the oxidation of xanthine to uric acid. Several feedback mechanisms can control the supply of xanthine and thereby the corresponding uric acid production [32]. For example, an increased urinary excretion of xanthine [33] or degradation of xanthine to xanthosine monophosphate by certain hypoxanthineguanine phosphoribosyltransferase [34] decreases the xanthine concentration. If this is the case, increased oxidation of hypoxanthine to xanthine and the associated harmful accumulation of ROS will not lead to an increased uric acid production. In the future a systematic approach, integrating the supply of hypoxanthine and xanthine and the involved pathways might be a more accurate way to determine uric acid production.

After adjustment for potential confounders (including serum uric acid) the association between urinary uric acid excretion and hypertension remained significant (Table 2, model 3). Further adjustment for BMI $(P=0.80)$ or waist-tohip ratio $(P=0.45)$ attenuated the association. This might be explained by the fact that adiposity increases xanthine oxidoreductase activity in mice, thus leading to overproduction of uric acid [26]. Adjustment for BMI or waist-to-hip ratio (measure for abdominal visceral fat), might, therefore, lead to overadjustment. Further research is required to examine the influence of adiposity and visceral fat on uric acid production and its association with hypertension. The associations of serum uric acid with blood and hypertension were not attenuated after including BMI or waist-to-hip ratio in the fully adjusted model. This is in line with the idea that serum uric acid concentration does not reflect uric acid production, as an increased uric acid production is compensated by increased excretion to maintain serum uric acid within the normal range.

In the present study, serum uric acid and urinary uric acid excretion were associated with MAP but not with PP. MAP is the steady component of BP reflecting vascular resistance, which can be increased by inhibiting the vasodilator nitric oxide. As previously described, several plausible mechanisms have been shown to link uric acid with a decrease in the bioavailability of nitric oxide. PP, the pulsatile component of $\mathrm{BP}$, increases as a consequence of prolonged exposure to increased vascular resistance and elevated BP. This results in remodeling of the vascular extracellular matrix [35,36], stiffening of the arteries and ultimately a loss in vascular compliance. Thus far, no prior studies investigated the association between uric acid and $\mathrm{PP}$ in depth [37-42]. Previous studies, investigated the association between uric acid and arterial stiffness. In line with the current results, a study conducted in a subset of The Maastricht Study population $(n=614)$, showed no association of serum uric acid with stiffness of the aorta, or the carotid or femoral artery [43]. Nonetheless, conclusive evidence cannot be provided as the literature shows disparate results [44-48]. We, therefore, emphasize the need for further studies addressing the role of uric acid on PP and arterial stiffness. In particular longitudinal studies, including middle-aged individuals, as uric acid may lead to early changes in arterial stiffness and subsequently to elevated PP, but may have less influence once vascular damage is permanent [49].

The use of 24-h ambulatory BP measurements and the adjustment for a large number of carefully measured potential confounders are major strengths of our study. Our study also has some limitations which should be considered. We 
would like to emphasize the need for further research validating urinary uric acid excretion as a proxy for uric acid production. Furthermore, we proposed that accumulation of ROS is a potential underlying mechanism linking increased uric acid production with elevated BP, but from the present study no conclusion can be drawn concerning the actual mechanism. Owing to the cross-sectional nature of this study, causal relationships could not be determined. In addition, because of missing data, we had to exclude almost 900 participants. Although we assumed the random nature of these missing because most values were missing because of logistic factors (e.g. the temporary unavailability of ambulatory BP monitors), the excluded individuals had a higher prevalence of (pre)diabetes and hypertension (Table 1). Furthermore, serum uric acid and 24-h urinary uric acid excretion was only determined once. As uric acid concentrations can vary between days, multiple measures would have been more accurate. Finally, our study population consisted of relatively more individuals with T2DM between $40-75$ years of age; therefore, the results might not be representative for the general population.

In conclusion, we found evidence for associations between serum uric acid and urinary uric acid excretion with ambulatory MAP and hypertension. By studying urinary uric acid excretion, we aimed to investigate whether an increased uric acid production was, independent of serum uric acid, associated with BP. Finding significant associations supports our hypothesis, highlighting the need for further investigation on increased uric acid production and its effect on urinary uric acid excretion and BP.

\section{AGKNOWLEDGEMENTS}

The study was supported by the European Regional Development Fund via OP-Zuid, the Province of Limburg, the Dutch Ministry of Economic Affairs (grant 31O.041), Stichting De Weijerhorst (Maastricht, The Netherlands), the Pearl String Initiative Diabetes (Amsterdam, the Netherlands), the Cardiovascular Center (CVC, Maastricht, The Netherlands), CARIM School for Cardiovascular Diseases (Maastricht, The Netherlands), CAPHRI School for Public Health and Primary Care (Maastricht, The Netherlands), NUTRIM School for Nutrition and Translational Research in Metabolism (Maastricht, The Netherlands), Stichting Annadal (Maastricht, The Netherlands), Health Foundation Limburg (Maastricht, The Netherlands) and by unrestricted grants from Janssen-Cilag B.V. (Tilburg, The Netherlands), Novo Nordisk Farma B.V. (Alphen aan den Rijn, The Netherlands), and Sanofi-Aventis Netherlands B.V. (Gouda, The Netherlands)

\section{Conflicts of interest}

There are no conflicts of interest.

\section{REFERENCES}

1. Grayson PC, Kim SY, LaValley M, Choi HK. Hyperuricemia and incident hypertension: a systematic review and meta-analysis. Arthritis Care Res (Hoboken) 2011; 63:102-110.

2. Wang J, Qin T, Chen J, Li Y, Wang L, Huang H, Li J. Hyperuricemia and risk of incident hypertension: a systematic review and meta-analysis of observational studies. PloS One 2014; 9:e114259.
3. Yu MA, Sánchez-Lozada LG, Johnson RJ, Kang DH. Oxidative stress with an activation of the renin-angiotensin system in human vascular endothelial cells as a novel mechanism of uric acid-induced endothelial dysfunction. J Hypertens 2010; 28:1234-1242.

4. McCord JM, Fridovich I. The reduction of cytochrome c by milk xanthine oxidase. J Biol Chem 1968; 243:5753-5760.

5. Corry DB, Eslami P, Yamamoto K, Nyby MD, Makino H, Tuck ML. Uric acid stimulates vascular smooth muscle cell proliferation and oxidative stress via the vascular renin-angiotensin system. J Hypertens 2008; 26:269-275.

6. Zhang JX, Zhang YP, Wu QN, Chen B. Uric acid induces oxidative stress via an activation of the renin-angiotensin system in 3T3-L1 adipocytes. Endocrine 2015; 48:135-142.

7. Scheepers LE, Wei FF, Stolarz-Skrzypek K, Malyutina S, Tikhonoff V, Thijs L, et al. Xanthine oxidase gene variants and their association with blood pressure and incident hypertension: a population study. J Hypertens 2016; 34:2147-2154.

8. Puig JG, Torres RJ, de Miguel E, Sánchez A, Bailén R, Banegas JR. Uric acid excretion in healthy subjects: a nomogram to assess the mechanisms underlying purine metabolic disorders. Metabolism 2012; 61:512-518.

9. Schram MT, Sep SJ, van der Kallen CJ, Dagnelie PC, Koster A, Schaper $\mathrm{N}$, et al. The Maastricht Study: an extensive phenotyping study on determinants of type 2 diabetes, its complications and its comorbidities. Eur J Epidemiol 2014; 29:439-451.

10. O'Brien E, Coats A, Owens P, Petrie J, Padfield PL, Littler WA, et al. Use and interpretation of ambulatory blood pressure monitoring: recommendations of the British hypertension society. BMJ 2000; 320: 1128-1134.

11. Mancia G, Fagard R, Narkiewicz K, Redón JS, Zanchetti A, Böhm M, Christiaens T, et al., Task Force Members. 2013 ESH/ESC Guidelines for the management of arterial hypertension The Task Force for the management of arterial hypertension of the European Society of Hypertension (ESH) and of the European Society of Cardiology (ESC). J Hypertens 2013; 31:1281-1357.

12. Meaney E, Alva F, Miguel R, Meaney A, Alva J, Webel R, et al. Formula and nomogram for the sphygmomanometric calculation of the mean arterial pressure. Heart 2000; 84:64.

13. O'Brien E, Asmar R, Beilin L, Imai Y, Mallion JM, Mancia G, et al European Society of Hypertension recommendations for conventional, ambulatory and home blood pressure measurement. J Hypertens 2003; 21:821-848

14. Dubois D, Dubois EF. A formula to estimate the approximate surfacearea if height and weight be known 1916. Nutrition 1989; 5:303-311.

15. Worlh Health Organization. Definition and diagnosis of diabetes mellitus and intermediate byperglycemia. Geneva, Switzerland: World Health Organization; 2006.

16. Richtlijnen goede voeding 2015. 2015, Health Council of The Netherlands.(Gezondheidsraad)

17. Inker LA, Schmid CH, Tighiouart H, Eckfeldt JH, Feldman HI, Greene T, et al., CKD-EPI Investigators. Estimating glomerular filtration rate from serum creatinine and cystatin C. New Engl J Med 2012; 367:20-29.

18. Takahashi S, Moriwaki Y, Yamamoto T, Tsutsumi Z, Ka T, Fukuchi M. Effects of combination treatment using antihyperuricaemic agents with fenofibrate and/or losartan on uric acid metabolism. Ann Rheum Dis 2003; 62:572-575.

19. Hamada T, Ichida K, Hosoyamada M, Mizuta E, Yanagihara K, Sonoyama K, et al. Uricosuric action of losartan via the inhibition of urate transporter 1 (URAT1) in hypertensive patients. Am J Hypertens 2008; 21:1157-1162.

20. Chanard J, Toupance O, Lavaud S, Hurault de Ligny B, Bernaud C, Moulin B. Amlodipine reduces cyclosporin-induced hyperuricaemia in hypertensive renal transplant recipients. Nephrol Dial Transplant 2003; 18:2147-2153.

21. Ogata N, Fujimori S, Oka Y, Kaneko K. Effects of three strong statins (atorvastatin, pitavastatin, and rosuvastatin) on serum uric acid levels in dyslipidemic patients. Nucleosides Nucleotides Nucleic Acids 2010; 29:321-324.

22. Brand FN, McGee DL, Kannel WB, Stokes J 3rd, Castelli WP. Hyperuricemia as a risk factor of coronary heart disease: the Framingham Study. Am J Epidemiol 1985; 121:11-18.

23. Kannel WB. Metabolic risk factors for coronary heart disease in women: perspective from the Framingham Study. Am Heart J 1987; 114:413-419. 
24. Watanabe S, Kang DH, Feng L, Nakagawa T, Kanellis J, Lan H, et al. Uric acid, hominoid evolution, and the pathogenesis of salt-sensitivity. Hypertension 2002; 40:355-360.

25. Samimi A, Ramesh S, Turin TC, MacRae JM, Sarna MA, Reimer RA, et al. Serum uric acid level, blood pressure, and vascular angiotensin II responsiveness in healthy men and women. Physiol Rep 2014; 2:.

26. Tsushima Y, Nishizawa H, Tochino Y, Nakatsuji H, Sekimoto R, Nagao $\mathrm{H}$, et al. Uric acid secretion from adipose tissue and its increase in obesity. J Biol Chem 2013; 288:27138-27149.

27. Hosomi A, Nakanishi T, Fujita T, Tamai I. Extra-renal elimination of uric acid via intestinal efflux transporter BCRP/ABCG2. PloS One 2012; 7:e30456.

28. Matsuo H, Takada T, Nakayama A, Shimizu T, Sakiyama M, Shimizu S, et al. ABCG2 dysfunction increases the risk of renal overload hyperuricemia. Nucleosides Nucleotides Nucleic Acids 2014; 33:266-274.

29. Uhlen M, Fagerberg L, Hallström BM, Lindskog C, Oksvold P, Mardinoglu A, et al. Proteomics. Tissue-based map of the human proteome. Science 2015; 347:1260419.

30. Takada T, Ichida K, Matsuo H, Nakayama A, Murakami K, et al. ABCG2 dysfunction increases serum uric acid by decreased intestinal urate excretion. Nucleosides Nucleotides Nucleic Acids 2014; 33:275-281.

31. Sorensen LB. Degradation of uric acid in man. Metabolism 1959; 8: $687-703$.

32. Lane AN, Fan TW. Regulation of mammalian nucleotide metabolism and biosynthesis. Nucleic Acids Res 2015; 43:2466-2485.

33. Puig JG, Mateos FA, Jiménez ML, Ramos TH. Renal excretion of hypoxanthine and xanthine in primary gout. Am J Med 1988; 85:533-537.

34. Curto R, Voit EO, Sorribas A, Cascante M. Mathematical models of purine metabolism in man. Math Biosci 1998; 151:1-49.

35. Intengan HD, Schiffrin EL. Vascular remodeling in hypertension: roles of apoptosis, inflammation, and fibrosis. Hypertension 2001; 38:581-587.

36. Mulvany MJ. Vascular remodelling of resistance vessels: can we define this? Cardiovasc Res 1999; 41:9-13.

37. Casiglia E, Tikhonoff V, Mazza A, Piccoli A, Pessina AC. Pulse pressure and coronary mortality in elderly men and women from general population. J Human Hypertens 2002; 16:611-620.

38. Inoue $\mathrm{T}$, Matsuoka $\mathrm{M}$, Nagahama $\mathrm{K}$, Iseki $\mathrm{C}$, Touma $\mathrm{T}$, Iseki $\mathrm{K}$, et al. Cardiovascular risk factors associated with pulse pressure in a screened cohort in Okinawa, Japan. Hypertens Res 2003; 26:153-158.

\section{Reviewers' Summary Evaluations \\ Referee 1}

In a relatively large sample size, the study showed that serum concentration and urinary excretion of uric acid were independently associated with hypertension and ambulatory blood pressure. Twenty-four-hour urinary excretion of uric acid can be considered as a proxy for uric acid production. This study therefore raised a very good hypothesis that should be tested in future prospective studies on the underlying mechanisms for the possible role of uric acid production in the pathogenesis of hypertension.
39. Tsioufis C, Kyvelou S, Dimitriadis K, Syrseloudis D, Sideris S, Skiadas I, et al. The diverse associations of uric acid with low-grade inflammation, adiponectin and arterial stiffness in never-treated hypertensives. J Human Hypertens 2011; 25:554-559.

40. Jin YL, Zhu T, Xu L, Zhang WS, Liu B, Jiang CQ, et al. Uric acid levels, even in the normal range, are associated with increased cardiovascular risk: the Guangzhou Biobank Cohort Study. Int J Cardiol 2013; 168:2238-2241

41. Mazza A, Pessina AC, Gianluca P, Tikhonoff V, Pavei A, Casiglia E. Pulse pressure: an independent predictor of coronary and stroke mortality in elderly females from the general population. Blood Press 2001; 10:205-211.

42. Wiik BP, Larstorp AC, Høieggen A, Kjeldsen SE, Olsen MH, Ibsen H, et al. Serum uric acid is associated with new-onset diabetes in hypertensive patients with left ventricular hypertrophy: the LIFE study. $A m J$ Hypertens 2010; 23:845-851.

43. Wijnands JM, Boonen A, van Sloten TT, Schram MT, Sep SJ, Koster A, et al. Association between serum uric acid, aortic, carotid and femoral stiffness among adults aged 40-75 years without and with type 2 diabetes mellitus: the Maastricht Study. J Hypertens 2015; 33: $1642-1650$

44. Chen X, Li Y, Sheng CS, Huang QF, Zheng Y, Wang JG. Association of serum uric acid with aortic stiffness and pressure in a Chinese workplace setting. Am J Hypertens 2010; 23:387-392.

45. Ishizaka $\mathrm{N}$, Ishizaka $\mathrm{Y}$, Toda $\mathrm{E}$, Hashimoto $\mathrm{H}$, Nagai R, Yamakado M. Higher serum uric acid is associated with increased arterial stiffness in Japanese individuals. Atherosclerosis 2007; 192:131-137.

46. Kuo CF, Yu KH, Luo SF, Ko YS, Wen MS, Lin YS, et al. Role of uric acid in the link between arterial stiffness and cardiac hypertrophy: a cross-sectional study. Rheumatology (Oxford) 2010; 49:1189-1196.

47. Lim JH, Kim YK, Kim YS, Na SH, Rhee MY, Lee MM. Relationship between serum uric acid levels, metabolic syndrome, and arterial stiffness in korean. Korean Circ J 2010; 40:314-320.

48. Hsu PF, Chuang SY, Cheng HM, Sung SH, Ting CT, Lakatta EG, et al. Associations of serum uric acid levels with arterial wave reflections and central systolic blood pressure. Int J Cardiol 2013; 168: 2057-2063.

49. Feig DI. The role of uric acid in the pathogenesis of hypertension in the young. J Clin Hypertens (Greenwich) 2012; 14:346-352.

\section{Referee 2}

This is another nonpopulation-based cross-sectional study about a possible association between serum uric acid and arterial blood pressure levels (or diagnosis of hypertension). Here, urinary uric acid was used in multivariate model. The results are that, as expected, the two items are associated. Of course, the results cannot be extended tout court to any subjects, because the records shown are selected. Nevertheless, there is a certain interest in confirming a concept when two important risk factors or indicators such as serum uric acid and hypertension and their possible interaction -are investigated. 